\title{
Количественный кластерный ВЭЖХ анализ антоцианов
}

\author{
Васияров Г.Г. ${ }^{1}$, Дробь А.А. ${ }^{1,2}$, Титова Е.В. ${ }^{1}$, Староверов С.М. ${ }^{1,2}$ \\ ${ }^{1} 3 A O$ «БиоХимМак СТ», Москва \\ ${ }^{2}$ Московский государственный университет им М.В.Ломоносова, Москва \\ Поступила в редакцию 31.01.2017 г.
}

Предложен способ количественной оценки содержания антоцианов в лекарственных препаратах и БАД на основе черники методом градиентной ВЭЖХ. Показана возможность использования стандартов глюкозидов мальвидина и цианидина для определения содержания антоциановых кластеров (групп гликозидов антоцианидинов). Исследовано содержание антоцианов в лекарственном препарате Миртилене Форте ( $\mathrm{SiFi}$, Италия) и БАД Черника Форте с витаминами и цинком и с лютеином (Эвалар, Россия).

Ключевые слова: антоцианы, обращенно-фазовая ВЭЖХ, кластеры, черника.

\section{Quantitative cluster HPLC-analysis of anthocyanes}

\author{
Vasiyarov G.G. ${ }^{1}$, DrobA.A. ${ }^{1,2}$, Titova E.V. ${ }^{1}$, Staroverov S.M. ${ }^{1,2}$ \\ ${ }^{1} J S C$ «BioChemMack $S \& T »$, Moscow \\ ${ }^{2}$ Lomonosov Moscow State University, Moscow
}

\begin{abstract}
This work continues the studies evaluating the content of anthocyanins in natural raw materials, juices, wines, medicines and dietary supplements by gradient HPLC. In previous papers, it was first suggested method for determine the authenticity of samples by a relative (normalized) content of so-called clusters, i.e. groups of anthocyanidins glycosides with the same aglycone, with using the reversed-phase HPLC. In this study, the cluster approach was applied to calculate the content of anthocyanins in Bilberry Forte (Evalar, Russia) and drug Mirtilene Forte (SiFi, Italy). Cyanidin-glucoside and malvidin-glucoside (Sigma, USA) were used as the external standards. The content of the clusters with similar spectral characteristics $\left(1^{\text {st }}\right.$ group included Cyd, Pnd and the $2^{\mathrm{d}}-$ Mvd, Ptd, Dpd) were determined in accordance to the relevant standard. The obtained data were compared with the results of $\mathrm{pH}$-dependent differential spectrophotometry for the same samples. It was shown that the discrepancies did not exceed $20 \%$. Thus, the method of quantitative determination of anthocyanins in different samples using HPLC and cluster analysis can be recommended as an alternative and more informative method than the generally accepted differential spectrophotometry.
\end{abstract}

Keywords: anthocyanines, reversed-phase HPLC, bilberry, clusters

\section{Введение}

Антоцианы, содержащиеся во многих ягодах, фруктах и овощах, вызывают большой интерес у фармацевтов и химиков, поскольку обладают высокой биологической активностью и могут быть полезны для человека при лечении и профилактике целого ряда заболеваний. Вместе с тем задача их идентификации и количественного определения в различных объектах (соках, винах, экстрактах, лекарственных препаратах и т.д.) до сих пор окончательно не решена, ввиду большого разнообразия 
антоцианов и отсутствия (или дороговизны) соответствующих стандартов. В литературе описаны различные подходы при анализе антоцианов в различных смесях. Основным количественным методом расчета суммы антоцианов является дифференциальная $\mathrm{pH}-$-зависимая спектрофотометрия [1-3], основанная на измерении поглощения растворов антоцианов в определенных условиях (растворитель, $\mathrm{pH}$, длина волны) и сопоставления с поглощением стандартных растворов (обычно глюкозида Суd, экстинкция которого известна и считается общепризнанной). Этот метод используют и в нашей стране $[1,2]$. Очевидным недостатком метода является то, что он позволяет оценивать лишь суммарное содержание антоцианов.

При определении содержания отдельных компонентов в смесях необходимо использовать метод, позволяющий эти компоненты разделять, например, ВЭЖХ. Так, при контроле соковой продукции и БАД нормативные документы $[1,2]$ предписывают проведение ВЭЖХ только для подтверждения подлинности по составу антоцианов. С нашей точки зрения целесообразно применение этого метода и для количественного анализа БАД, и, тем более, для анализа фармпрепаратов, а также сырья, на основе которого изготавливают все эти средства. То есть требуется разработка универсального метода анализа, позволяющего с высокой степенью достоверности оценивать качественный и количественный состав антоцианов в различных субстанциях. Следует отметить, что классический подход с применением стандартных образцов всех разделяемых компонентов в данном случае практически нереализуем, поскольку либо какие-то из этих стандартов недоступны, либо очень дороги. Поэтому проблему количественной оценки содержания отдельных компонентов разные исследователи решают по-разному. Так, например, в работах Wrolstad и др. [3] общее содержание антоцианов в различных объектах рассчитывают по коммерческим стандартам либо Cyd-Glu, либо Mvd-Glu. Авторы демонстрируют, что при сравнении данных ВЭЖХ с данными спектрофотометрии наблюдаются значительные расхождения, доходящие до 500-700\%. Надежность этих данных, полученных в результате масштабного межлабораторного эксперимента, не подлежит сомнению, различия же связаны, по нашему мнению, с неверным методическим подходом при определении содержания антоцианов в режиме ВЭЖХ.

В Европейской Фармакопее [4] подлинность, а также суммарное содержание антоцианов и антоцианидинов в продукции на основе черники, оценивают по отношению к охарактеризованному независимым способом коммерческому экстракту. Такой подход надежен, но, во-первых, не дает возможности оценивать содержание каждого отдельного антоциана в смеси, а во-вторых, применим лишь для конкретного объекта (черники). В литературе описан [5] достаточно сложный в техническом отношении подход, сочетающий полупрепаративную ВЭЖХ с последующей pHзависимой колориметрией разделяемых компонентов.

Наше предложение сводится к тому, что все антоцианы, исходя из их строения, можно разделить на так называемые кластеры. Согласно нашей концепции, принадлежность антоциана к тому или иному кластеру определяется агликоном, или антоцианидиновым хромофором (наиболее распространены Pgd, Cyd, Dpd, Ptd, Pnd и Mvd) (рис. 1). В ранее опубликованных работах [6,7] нами впервые был продемонстрирован способ определения подлинности образцов по относительному (нормированному) содержанию в них соответствующих кластеров. В данном исследовании мы рассматриваем возможность использования кластерного подхода для количественной оценки содержания антоцианов в различных образцах. 


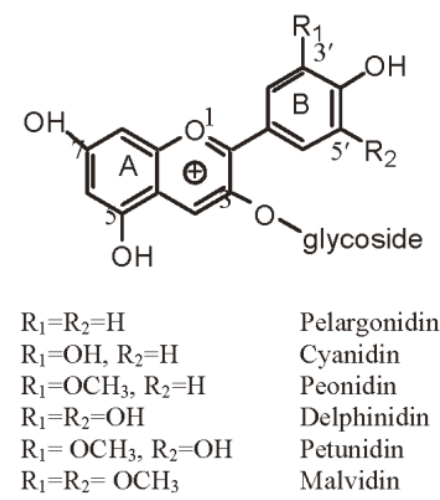

Рис. 1. Структура антоцианов

Известно, что черника наиболее богата антоцианами (в состав ее входят 15 антоцианов). Она и была выбрана основным объектом наших исследований. В предыдущих работах мы представили условия разделения всех 15 антоцианов черники (или 5 кластеров на основе Cyd, Dpd, Pnd, Ptd, Mvd, содержащих по 3 соответствующих гликозида) и показали возможность оценивать содержание всех компонентов по нормированным площадям пиков, определяя таким образом подлинность плодово-ягодного сырья и соковой продукции. Мы полагали, что при длине волны свыше 500 нм (что соответствует максимуму в спектрах антоцианов) вклад гликозидных остатков в экстинкцию будет ничтожно мал и существенно не повлияет на конечный результат при количественном определении антоциана. Идентификацию пиков на хроматограмме проводили, исходя из литературных данных [4] и основываясь на относительных временах удерживания соответствующих гликозидов внутри каждого кластера, подобно тому, как это было предложено в [8].

\section{Эксперимент}

Образцы. В работе использованы стандарты Cyd-Glu и Mvd-Glu (Sigma, США), лекарственный препарат Миртилене Форте (SiFi, Италия), БАД Черника Форте с витаминами и цинком и Черника Форте с лютеином (Эвалар, Россия). Концентрацию антоциана (Cyd-Glu или Mvd-Glu) в стандартном растворе определяется спектрофотометрически при 510 нм и рН 1 с использованием известных величин экстинкций.

Пробоподготовка. Таблетки Черника Форте в количестве 5 штук измельчали, взвешивали, растворяли в $5 \mathrm{~cm}^{3}$ элюента А (см. ниже) и пропускали через патрон Диапак Силикагель (ЗАО «БиоХимМак СТ», Россия) для удаления полярных соединений. Капсулы Миртилене Форте в количестве 3 штук измельчали, добавляли $200 \mathrm{~cm}^{3}$ элюента А, перемешивали и отделяли гидрофобные компоненты $30 \mathrm{~cm}^{3}$ изооктана на делительной воронке.

ВЭЖХ. Анализ проводили в градиентном режиме на хроматографе Azura (Knauer, Германия), снабженном спектрофотометрическим детектором и колонкой Диасфер 110-С18, 3.5 мкм, размером 4.6х150 мм (ЗАО «БиоХимМак СТ», Россия). Для обработки хроматограмм применяли программу ClarityChrom (версия 5.03.192, Чехия). В качестве элюента А использовали $\mathrm{HCOOH}-\mathrm{H}_{2} \mathrm{O}, 8.5 / 91.5$ (об.), элюента В - смесь НCOOH-MeOH-ACN-H ${ }_{2} \mathrm{O}, 8,5 / 22,5 / 22,5 / 41,5$ (об.). Форма градиента 15-33\% В за 35 мин. Поток $0.8 \mathrm{~cm}^{3} /$ мин. Длина волны детектора 510 нм. Температура $35^{\circ} \mathrm{C}$. 
Расчет суммарной массы антоцианов $\mathrm{m}$, мг на 1 таблетку (капсулу), производился по внешнему стандарту (Cyd-Glu или Mvd-Glu) по формуле:

$$
m=\sum \frac{S_{i} \cdot M_{i} \cdot C_{c m .} \cdot V_{\text {пробы }} \cdot R \cdot 1000}{S_{\text {ст. }} \cdot N},
$$

где $S_{i}$ - площадь пика антоциана; $M_{i}-$ молекулярная масса антоциана; $\mathrm{C}_{c m}-$ концентрация стандартного образца (для кластеров Dpd, Ptd и Mvd - это Mvd-Glu; для кластеров Cyd и Pnd - это Cyd-Glu) в растворе, определенная спектрофотометрически по экстинкции стандарта, моль/дм ${ }^{3} ; V_{\text {пробы }}$ - объем пробы, дм ${ }^{3} ; R-$ коэффициент разбавления; $S_{\text {ст. }}$ - площадь пика стандартного образца (для кластеров Dpd, Ptd и Mvd - это Mvd-Glu; для кластеров Cyd и Pnd - это Cyd-Glu); $N$ - количество таблеток (капсул), шт.

Спектрофотометрия. Анализ проводили на спектрофотометре SmartSpec Plus Spectrophotometer (Bio-Rad, CШA). Определение суммарного количества антоцианов производили по методу рН-дифференциальной спектрофотометрии [1]. Пробы были разбавлены так, чтобы значения оптической плотности находились в пределах 0.2-1.0.

Оптическую плотность суммы антоцианов рассчитывали, как разность оптических плотностей растворов при разных длинах волн и значениях $\mathrm{pH}$ по формуле:

$$
A=\left(A_{510}-A_{700}\right)_{p H 1,0}-\left(A_{510}-A_{700}\right)_{p H 4,5}
$$

Для расчета суммарной массы антоцианов $\mathrm{m}$, мг на 1 таблетку/капсулу использовали формулу:

$$
m=\frac{A \cdot M_{i} \cdot R \cdot V_{\text {пробы }} \cdot 1000}{\varepsilon \cdot l \cdot N}
$$

где $A$ - измеренная оптическая плотность суммы антоцианов; $M_{i}-$ молекулярная мacca Cyd-Glu или Mvd-Glu; $V_{\text {пробы }}$ - объем пробы, дм ${ }^{3} ; R$ - коэффициент разбавления; $\varepsilon$ - молярный коэффициент экстинкции (Cyd-Glu $26900\left[\text { моль·см/дм }{ }^{3}\right]^{-1}$ или Mvd-Glu 29000 [моль см/дм $\left.{ }^{3}\right]^{-1}$ ), $l$ - длина оптического пути кюветы, см; $N$ - количество таблеток/капсул.

\section{Обсуждение результатов}

Как уже отмечалось выше, при ВЭЖХ-анализе антоцианов исследователи сталкиваются с отсутствием большинства стандартов. Наиболее доступны глюкозиды мальвидина и цианидина. Именно их чаще всего используют в качестве эталонных [1-3]. Мы при количественных расчетах также применяли стандарты Cyd-Glu и Mvd-Glu. Но, в отличие от указанных выше авторов [3], использовали их избирательно. В связи с тем, что Суd и Рnd являются дизамещенными по ароматическому кольцу, a Mvd, Ptd, Dpd - тризамещенными (рис. 1), можно ожидать, что и экстинкции соответствующих антоцианов будут близки. Это подтверждают данные, приведенные в работе [9]. Таким образом, содержание двух кластеров оценивали по СуdGlu, a содержание трех других - по Mvd-Glu. C нашей точки зрения это позволило нивелировать «эффект переоценки» площадей пиков в многокластерных объектах, который наблюдался в работе [3].

Описанные в Европейской Фармакопее [4] условия разделения антоцианов черники мы адаптировали (по форме градиента) для своей колонки Диасфер 110C18. Проводя анализ в градиентном режиме ВЭЖХ при 510 нм, мы учитывали тот

$\boldsymbol{B}$ асияров и др. / Сорбционные и хроматографические процессы. 2017. Т. 17. № 2 
факт, что при этой длине волны существует так называемая изобестическая точка [10] и изменение состава элюента практически не влияет на экстинкции компонентов смеси.

Разработанный подход был опробован на лекарственном препарате «Миртилене Форте» (Италия) и БАД «Черника Форте» (Эвалар, Россия), в состав которых входит черника.

На рис. 2 представлены хроматограммы экстрактов, полученных из капсул Миртилене Форте и таблеток Черника Форте. На хроматограммах видно, что все компоненты разделяются достаточно хорошо. При этом входящая в состав Черники Форте карминовая кислота полностью отделяется от антоцианов.

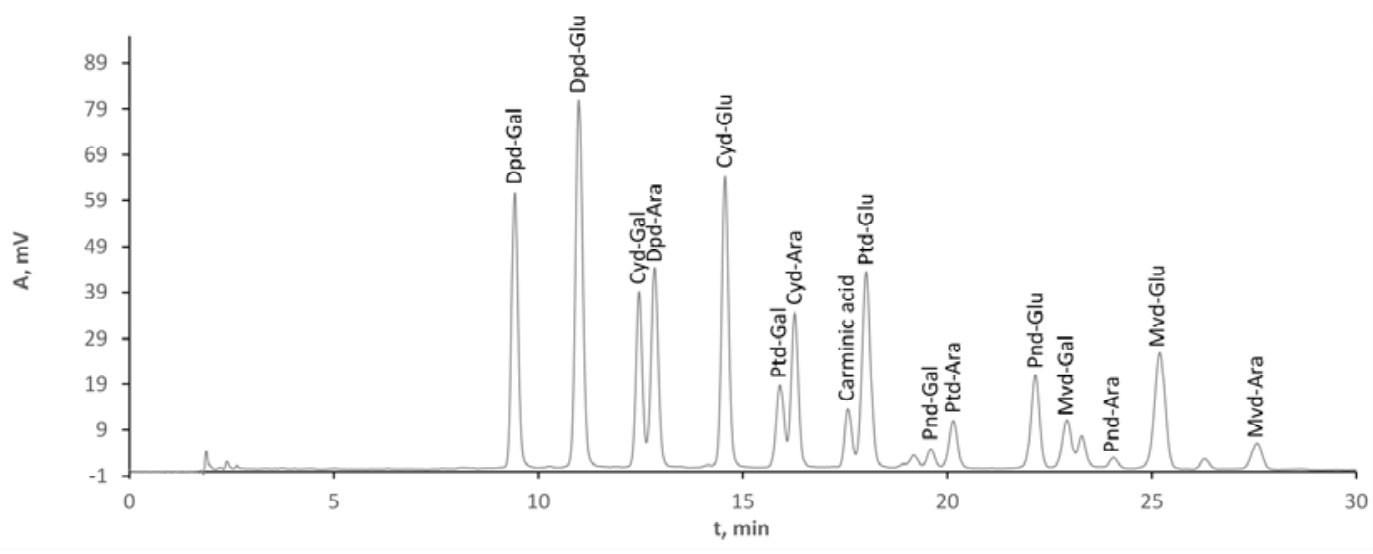

a

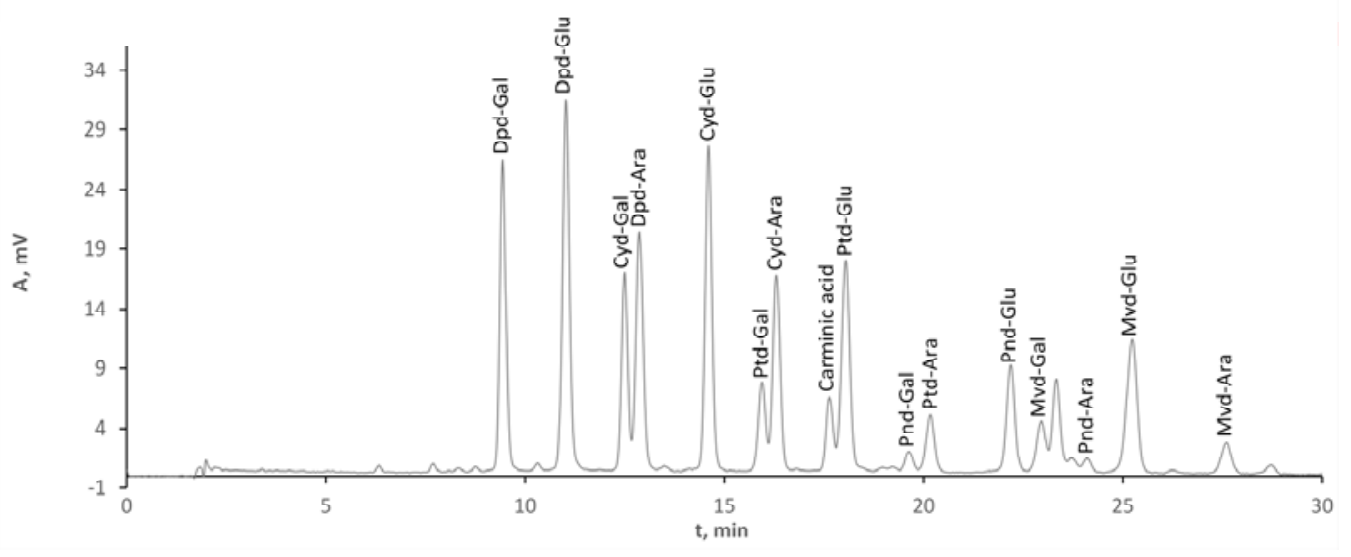

6

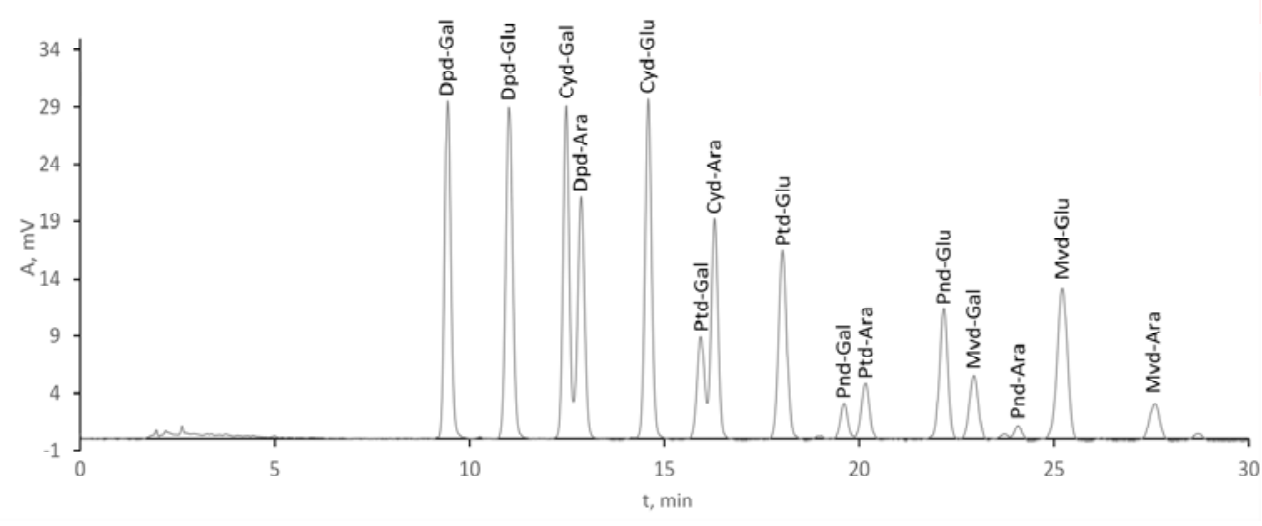

B

Рис.2. Хроматограммы образцов Черника Форте (Эвалар, Россия) с витаминами и цинком (a), с лютеином (б) и Миртилене Форте (SiFi, Италия) (в). 
Проведенные расчеты показали, что в 1 капсуле Миртилене Форте имеется 39 мг антоцианов, что вполне согласуется как с данными спектрофотометрического определения (38 мг), так и с техническим паспортом производителя (44 мг) (табл. 1). В то время как в таблетках Черника Форте обнаружен существенный недостаток антоцианов по сравнению с тем, какой указан в сопроводительной документации к таблеткам. При этом сходимость с данными спектрофотометрии удовлетворительная.

Таблица 1. Содержание антоцианов в препаратах на основе черники

\begin{tabular}{|c|c|c|c|c|}
\hline \multirow{3}{*}{ Название препарата } & \multicolumn{4}{|c|}{ Содержание антоцианов, мг/таб. (капс.) } \\
\hline & \multirow[b]{2}{*}{$\begin{array}{c}\text { Паспортные } \\
\text { данные }\end{array}$} & \multirow{2}{*}{$\begin{array}{c}\text { ВЭЖХ } \\
\begin{array}{c}\text { По предлагаемо- } \\
\text { му методу }\end{array}\end{array}$} & \multicolumn{2}{|c|}{ СФ } \\
\hline & & & По Cyd-Glu & Пo Mvd-Glu \\
\hline $\begin{array}{l}\text { Черника Форте с ви- } \\
\text { таминами и цинком }\end{array}$ & 0.3 & 0.19 & 0.16 & 0.17 \\
\hline $\begin{array}{c}\text { Черника Форте с лю- } \\
\text { теином }\end{array}$ & 0.5 & 0.38 & 0.31 & 0.31 \\
\hline $\begin{array}{l}\text { Миртилене Форте } \\
\text { (капс.) }\end{array}$ & 44.2 & 39.0 & 37.4 & 38.2 \\
\hline
\end{tabular}

В целом, по сравнению с данными Wrolstad [3], полученные результаты свидетельствуют о преимуществах предложенного нами способа количественной оценки содержания антоцианов в различных объектах, позволяющего более точно определять, как сумму антоцианов, так и содержание отдельных компонентов. Исследования в этом направлении будут продолжены на примере других объектов.

\section{Заключение}

В режиме обращенно-фазовой ВЭЖХ в условиях градиентного элюирования разделены 15 антоцианов черники. Предложен способ количественной оценки содержания антоцианов, основанный на объединении в группы (кластеры) гликозидов антоцианидинов с общим агликоном и использовании в качестве внешних стандартов антоцианов с похожими спектральными характеристиками (Mvd-Glu для кластеров Mvd, Ptd, Dpd и Cyd-Glu для кластеров Суd и Pnd). На примере двух БАД и лекарственного препарата, содержащих антоцианы черники, показана возможность применения данного подхода для количественного анализа антоцианов в различных объектах и его преимущества перед описанными в литературе методами.

\section{Список литературы}

1. ГОСТ Р 53773-2010. Продукция соковая. Методы определения антоцианов. Стандартинформ. М. 2010.

2. Руководство по методам контроля качества и безопасности биологически активных добавок к пище. Р 4.1.1672-2004. Минздрав России, М. 2004.

3. Lee J., Rennaker C., Wrolstad R.E. // Food Chem. 2008. Vol. 110. pp.782-786.

4. EuPh 8.0. Vol.1. pp.1250-1252.
5. Wang H. // J. Sep. Sci. 2014. Vol. 37. pp. 2535-2544.

6. Васияров Г.Г., Дробь А.А., Титова Е.В. // Материалы тезисов IV Bсеросс. симпоз. «Кинетика и динамика обменных процессов». Сочи. 2015. С. 87-88.

7. Васияров Г.Г., Дробь А.А., Титова Е.В., Староверов С.М. // Сорбиионные и хроматографические проиессы, 2016. Т. 16. № 4. C. 488-495. 
8. Дейнека В.И., Григорьев А.М., Дейнека Л.А., Шапошник Е.И. и др. // Заводская лаборатория. Диагностика материалов, 2006. T. 72. № 3. С. 16-20.

9. Григорьев А.М., Рудаков О.Б., Селеменев В.Ф. Особенности хроматографического поведения антоцианов в условиях гидрофильной обращенно-фазовой ВЭЖХ. Оп-

\section{References}

1. GOST R 53773-2010. Produktsiya sokovaya. Metody opredeleniya antotsianov. Standartinform, M., 2010

2. Rukovodstvo po metodam kontrolya kachestva i bezopasnosti biologicheski aktivnykh dobavok k pishche, R 4.1.1672-2004, Minzdrav Rossii, M., 2004.

3. Lee J., Rennaker C., Wrolstad R.E., Food Chem., 2008, Vol.110, pp.782-786.

4. $\mathrm{EuPh}$ 8.0. Vol.1, pp. 1250-1252.

5. Wang H., J. Sep. Sci. 2014, Vol. 37, pp. 2535-2544.

6. Vasiyarov G.G., Drob' A.A., Titova E.V., sb. tez. dokl. na IV Vserossiiskom simpoz. «Kinetika i dinamika obmennykh protsessov», Sochi, 2015. pp. 87-88.

7. Vasiyarov G.G., Drob' A.A., Titova E.V., Staroverov S.M., Sorbtsionnye i khroma- ределение антоцианов в сокосодержащих напитках, Хроматография на благо России. М. Граница, 2007. С. 114-134.

10. Дейнека Л.А., Шапошник Е.И., Гостищев Д.А. и др. // Сорбчионные и хроматографические проиессы. 2009. Т. 9. № 4. С. 529-536

tograficheskie protsessy, 2016, Vol. 16, No 4, pp. 488-495.

8. Deineka V.I., Grigor'ev A.M., Deineka L.A., Shaposhnik E.I. et al., Zavodskaya laboratoriya. Diagnostika materialov, 2006, Vol. 72, No 3, pp. 16-20.

9. Grigor'ev A.M., Rudakov O.B., Selemenev V.F. Osobennosti khromatograficheskogo povedeniya antotsianov $\mathrm{v}$ usloviyakh gidrofil'noi obrashchenno-fazovoi VEZhKh. Opredelenie antotsianov $\mathrm{v}$ sokosoderzhashchikh napitkakh, Khromatografiya na blago Rossii, M., Granitsa, 2007, pp. 114-134.

10.Deineka L.A., Shaposhnik E.I., Gostishchev D.A., Sorbtsionnye i khromatograficheskie protsessy, 2009, Vol. 9, No 4, pp. 529536

Vasiyarov Georgii G. - Head of chromatography department JSC "BioChemMack S\&T", Moscow

Drob Alexandre A. - Laborant, JSC "BioChemMack S\&T", Student, Chemistry department, Lomonosov State University, Moscow

Titova Elena V.- Ph.D. (chemistry), Leadering Researcher, JSC "BioChemMack S\&T"

Staroverov Sergey M.- grand Ph.D (chemistry), CEO JSC "BioChemMack S\&T", Head of Laboratory "New chemical technologies for medicine", Chemistry department, Lomonosov State University Moscow, email:staroverov@bcmst.ru 